\title{
Formalized Resolution of the Scientific Task for Improving the Effective Planning Special Purpose Unmanned Aerial Vehicles Routes of Tactical Level
}

\author{
Ruslan Hryshchuk ${ }^{1}$, Yuriy Bondarenko ${ }^{1}$, Vadim Horbach ${ }^{1}$ \\ ${ }^{1}$ Serhiy Korolyov Zhytomyr Military Institute \\ 22 Prospect Myru, Zhytomyr, 10004, Ukraine
}

DOI: $10.22178 /$ pos. $42-1$

LCC Subject Category: UG730-735

Received 28.12.2018

Accepted 25.01.2019

Published online 31.01.2019

Corresponding Author:

Vadim Horbach

g.-vadim@ukr.net

(C) 2019 The Authors. This article is licensed under a Creative Commons Attribution 4.0 License @) (1)

\begin{abstract}
In the article, the features of application of special purpose unmanned aerial vehicles of the tactical level have resulted during the operation of the joint forces. The role of routes planning of special purpose unmanned aerial vehicles of tactical level in the conditions of a concrete battle situation is determined. The necessity of the mathematical development for planning a flight route of special purpose unmanned aerial vehicles is justified. Essence and maintenance of scientific task are set. Its formalized setting is guided.
\end{abstract}

Keywords: unmanned aerial vehicle; planning a flight route; factors of influence; criterion; optimizing.

\section{INTRODUCTION}

Armed aggression and the use by the Russian Federation the territory of the Eastern Ukraine to test the latest weaponry requires an adequate response to these challenges. The special purpose unmanned aerial vehicles, mainly tactical level, are used for intelligence purpose support for the execution of combat missions. However, there are a number of factors that determine the success of the task accomplished by unmanned aerial vehicles. These include the following factors qualitative planning of the flight route, skillful actions, and piloting skills of the aircraft, the availability of programmed mathematical tools for automating the operator's actions, and others. Having analyzed the procedure for planning the flight route, one can conclude that there is a high degree of subjectivity in the actions of the person planning to use the unmanned aerial vehicles.

The technologies associated with unmanned aerial vehicles are advanced, therefore, algorithms and software products for scheduling special purpose unmanned aerial vehicles of flight routes are not available. The software and mathematical tools used in the unmanned aerial vehicles in the operation of the united forces (OUF) on the territory of Ukraine have a little adaptation to possible influences on the aircraft in combat conditions. Therefore, the development of effective methods for the use of unmanned aerial vehicles, further improving the efficiency operating prototypes of unmanned aerial vehicles is a topical task. In particular, it is necessary to study the question of planning a flight route of special purpose unmanned aerial vehicles and the possibility of its further optimization.

The analysis of the last researches and publications $[5,4,3]$ routined that such factors as the introduction of the new robotic and unmanned systems, technologies of decision making support, development of new standards of armament and military technique, create a new problem of scientific researches for a military sphere. It is directed on the application of these researches including the increase of efficiency of reconnaissance unmanned aerial vehicles use. For the construction of optimum flight route such mathematical algorithm is used: integer dynamic programming [1], ant algorithm [10], the algo- 
rithm for finding solutions on graphs, queryresponse-consent model [6], etc. These methods and techniques have a number of advantages and disadvantages while applying them for optimizing the flight route of the aircraft.

However, from the analysis of available sources, it has been found that in most of them there are no adequate models for choosing a special purpose unmanned aerial vehicles flying in the conditions of a particular combat picture, or describing the factors of influencing the aircraft from the subjective view of the person planning the flight. The experience of practical use of unmanned aerial vehicles in combat proves $[9,3,13]$ that these factors may contradict each other by creating uncertainty while giving the priority to any of them during the planning process.

Thus, the described problem according to the analysis of publications on the subject of the study is of great importance for science and practice, remains relevant and needs to be solved.

The purpose of our work formalized resolution of the scientific task for improving the effective planning special purpose unmanned aerial vehicles routes of the tactical level.

\section{RESULTS AND DISCUSSION}

The purpose of this work is to formalize the scientific task of improving the planning of the specially designated unmanned aerial vehicles flight route by optimizing the criteria for selecting the flight path of the aircraft during the planning of the use of unmanned aerial vehicles. The aims and objectives of the research. The final outcome of the intelligence will depend on the number of factors affecting the aircraft in combat conditions. The specific combat picture is a set of criteria that should be taken into account while planning the flight route. Therefore, the decision of this task will contribute to improving the quality of the tasks performed by these units. At the present time, unmanned aerial vehicles servicemen, while planning, make a choice of flight routes with a high proportion of subjectivity, indicating the possibility of mathematically unreasonable solutions. A large amount of information is taken into account by the person planning the flight route, the criteria of influence that can contradict each other, make the task difficult in terms of justification of the decision.
So, in the final case, the option of constructing a flight will depend on: the time of reconnaissance tasks execution, the probability of the unmanned aerial vehicles defeat, the maximum effectiveness of the intelligence, the number of enemy intelligence objects needed to be explored and their priority, the flight range or permissible battery level (fuel reserve) unmanned aerial vehicles etc.

Consider the current state of technology development associated with increasing the effectiveness of the use of special purpose unmanned aerial vehicles, which were used in wartime and modern armed conflicts [13]. According to a definition, of the American experts, the air remotely controlled system should be characterized by lack of personnel in the area of hostilities; the possibility of a full cycle (detection, classification, maintenance and fire damage) of tasks during strikes on land targets in the designated area; long flight duration to ensure continuity of intelligence (observation); small indicators of visibility; the ability to operate in difficult conditions of the situation. In this regard, further enhancement of the combat capabilities of the unmanned aerial vehicles, along with the improvement of onboard reconnaissance and sighting systems, equipment for data transmission and information exchange, provides an increase of the autonomy of their actions. The experience of applying the special purpose unmanned aerial vehicles by in NATO countries in combat conflicts has corrected the prospects for the development of unmanned aerial vehicles. New requirements for control stations, the presence of at least 2 channels of direct communication with the unmanned aerial vehicles, the reliability of the coding of the channels for the transmission of intelligence data, the ability to perform tasks in a complicated electronic environment, and so on.

According to the given information, the success of the unmanned aerial vehicles depends on a proper assessment of the complex capabilities, an understanding the tactical picture in the area of operation, the number of enemy objects that are needed to be explored, and the means of defeating the unmanned aerial vehicles. Analyzing the experience of defeating the unmanned aerial vehicles of the units of the Armed Forces of Ukraine $[9,3,13]$ and the large number of factors that influence the aircraft, we can conclude that the solution of the problem of optimization of the planning flight routes of special purpose unmanned aerial vehicles will allow increasing the effectiveness of unmanned aerial vehicles. At 
present, the mathematical support, flight planning process is not perfect, which makes it impossible to take into account the factors of influence on the aircraft. Thus, today there is an objective contradiction between the imperfection of the mathematical provision of the planning process, which is used in the OUF and high techno- logical capabilities of this process necessary for the realities for combat use. From the analysis [2, $12,7]$ of the graphical representation of the problem, planning the flight route of special purpose unmanned aerial vehicles of the tactical level is represented as a scheme (Figure 1 ).

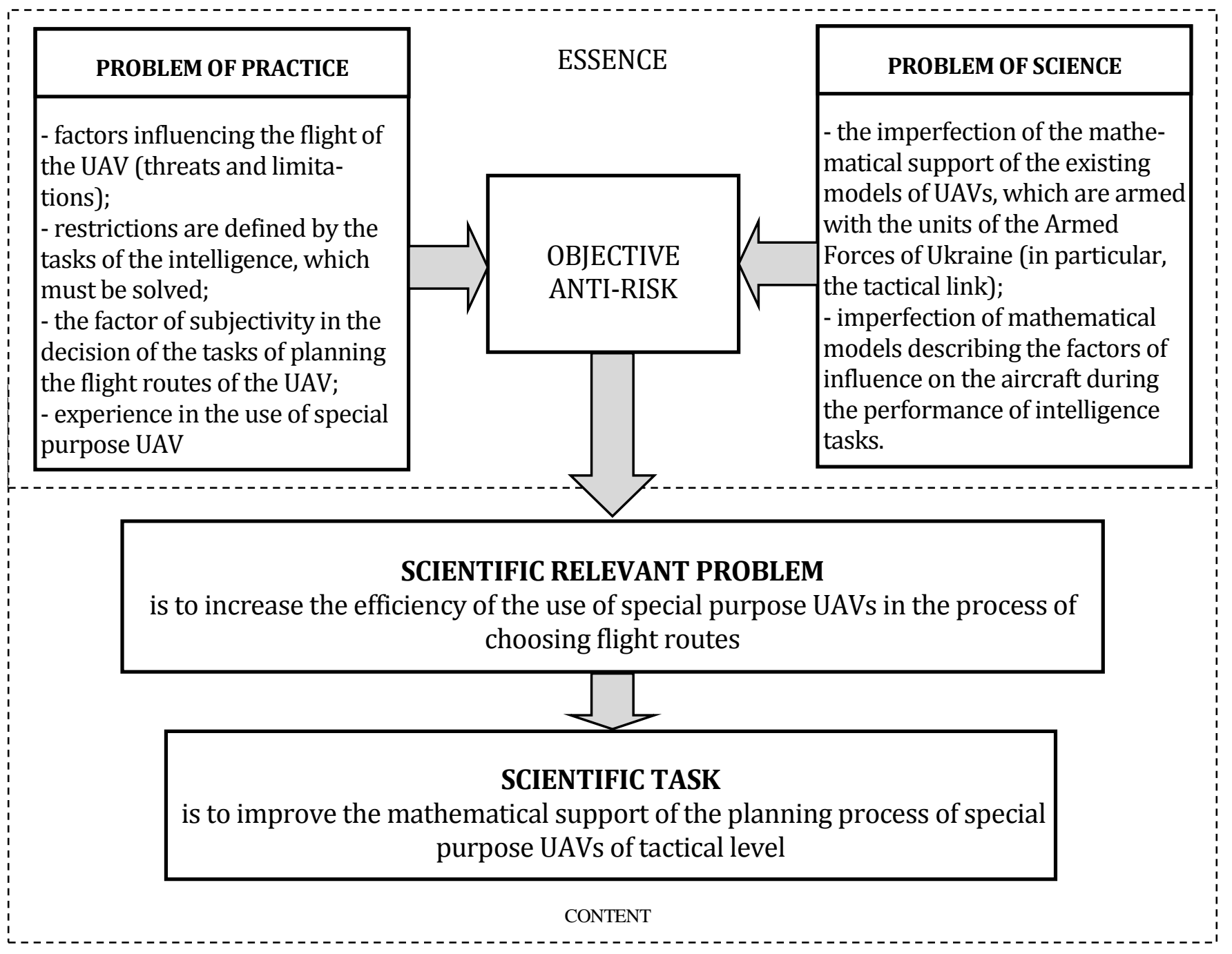

Figure 1 - The essence and the content of a scientific task

First of all, to solve this scientific problem, it is necessary to make a mathematical statement of the problem. From the analysis of the factors influencing the flight of the unmanned aerial vehicles, one should distinguish between those that can be expressed through the criterial dependence. The set of partial criteria $\mathrm{k}_{1}, \mathrm{k}_{2}, \ldots, \mathrm{k}_{\mathrm{n}}$, reflects the mathematical interpretation of the factors influencing the flight unmanned aerial vehicles. They will have an impact on the choice of the flight plan of the unmanned aerial vehicles during the planning phase. Taking into account the threats and limitations of the natural and technical nature in the formalized form, the crite- ria for choosing the flight route of the special purpose unmanned aerial vehicles of a tactical level can be summarized as follows (1):

$$
f_{j}\left(k_{1}, k_{2}, \ldots, k_{n}\right)=\theta_{j}, j=\overline{1, m},
$$

where $f_{j}$ - the function of the criteria for choosing the route flight from the limits of the aircraft;

$\theta_{j}$ - the function of the criteria for choosing the route of a flight from the aircraft's limits. 
It is necessary to identify the main criteria from the general list and they will influence the choice of the flight path of the unmanned aerial vehicles. Since the person planning the flight route taking into account these criteria, in the general case, the task he solves will have the form of the scheme (2).

$$
\left\{\left\{K_{i}\right\}, Y\right\} \rightarrow P^{*}
$$

where $P^{*}$ - the optimal value of the main criteria for choosing the flight path of the aircraft (one or more);

\section{$K$ - optimized criteria;}

$Y$ - the function of choice or the rule of giving an advantage to this set of coefficients on the set of alternatives [6].

In the theory of decision-making, a vector approach is common, during which, for this case, it is not possible to evaluate the plan of the flight path of the unmanned aerial vehicles as a whole, but after analyzing the list of the main criteria of its choice. In contrast to the frankly subjective approach to solving this problem, it is possible to formalize the decision-making process for planning the flight path of the unmanned aerial vehicles. The difficulty may be caused by the tion $Y$, that is used by the operator during the planning. There is a need for further harmonization of possible trade-offs of losses of certain criteria and their magnitude. In view of the polymetric of partial criteria and the multi-directional extremist effect on the choice of the specialpurpose unmanned aerial vehicles route, consider a search option for a generalized criterion $P^{*}$ for a nonlinear compromise scheme [11] and find their optimal value (3).

$$
P^{*}=\operatorname{argmin} \sum_{i=1}^{m} \alpha_{i_{0}}\left(1-\varphi_{i_{0}}\left(K_{i}\right)\right)^{-1},
$$

$K_{i} \in \Omega$

where $P^{*}$ - optimal value of the main the criteria for the impact on unmanned aerial vehicles;

$K_{i}$ - optimized criteria;

$\Omega$ - area possible values of optimized criteria;

$\varphi_{i_{0}}\left(K_{i}\right)$ - normalized function $K$-th partial criterion of optimality; $\alpha_{i_{0}}$ - normalized weighting factor of the importance of each of the main criteria for the impact on unmanned aerial vehicles;

$n$ - number of partial optimality criteria.

A variant of the task solution of curtailing criteria will be called effective if there are no better solutions for it. Due to the factors influencing the unmanned aerial vehicles, the limitation of technical capabilities and the requirements for the reconnaissance task, attention should be paid to the criteria that the operator takes into account during the planning of the flight of a special purpose aircraft. The quality of intelligence information is a generalized criterion that reflects the probabilistic amount of intelligence information that depends on the given or required resolution of photo and video information and the optimum airspeed. The total length of the flight route is a criterion that reflects the numerical value of the distance that the aircraft will take during the execution of intelligence tasks.

The number of explored intelligence objects (IO) is a quantitative value that reflects the amount of single (group) intelligence objects were that explored with a given quality.

Priority of intelligence objects is a generalized criterion that characterizes the importance of intelligence objects in accordance with the requirements for the priority of the defeat and the intelligence task. The probability of defeat of unmanned aerial vehicles is the criterion, which represents the sum of probabilities that characterize the process of implementing the unmanned aerial vehicles for intelligence task, and provides an opportunity to assess the risks of aircraft losses. The mathematical expectation of the number of explored intelligence objects is a criterion that characterizes the mathematical expectation of qualitatively proven intelligence objects in the flight path of the unmanned aerial vehicles.

Let the criteria that have a greater impact on the choice of the special flight plan for the unmanned aerial vehicles will be: the quality of intelligence

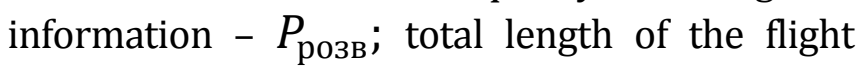
route $-L_{\text {марш }}$; number of explored IO $-N_{\mathrm{OP}}$; priority IO $-N_{\text {пріор }}$;probability of defeat unmanned aerial vehicles $-P_{\text {ураж }}$; mathematical 
expectation of the number of explored IO $M_{N \mathrm{OP}}$ and other.

Then formally the task of optimizing the data of the criteria of influence on the choice of the route should be as follows (4):

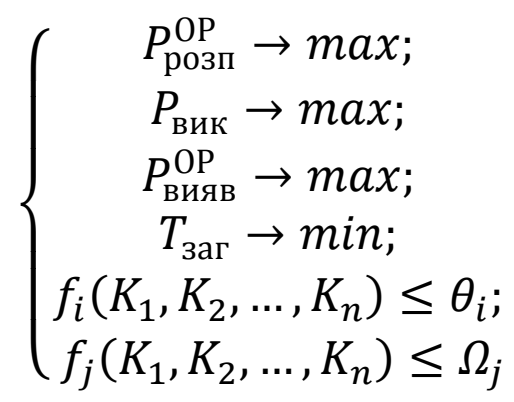

where $\theta_{i}$ - limitation of technical capabilities of unmanned aerial vehicles, taken into account when solving the problem;

$\Omega_{j}$ - limitations are stipulated by the requirements of intelligence task for the unmanned aerial vehicles.

In order to solve the problems of increasing the efficiency of the use of special purpose unmanned aerial vehicles with consideration of criteria influencing the choice of flight path of aircraft at the planning stage, a structural-logical scheme of research was developed (Figure 2).

\section{ACTUALITY}

is due to the need to resolve the controversy when taking into account the criteria affecting the choice of the flight path of the reconnaissance aircraft tactical level, and the absence (imperfection) of the appropriate mathematical support for solving this problem

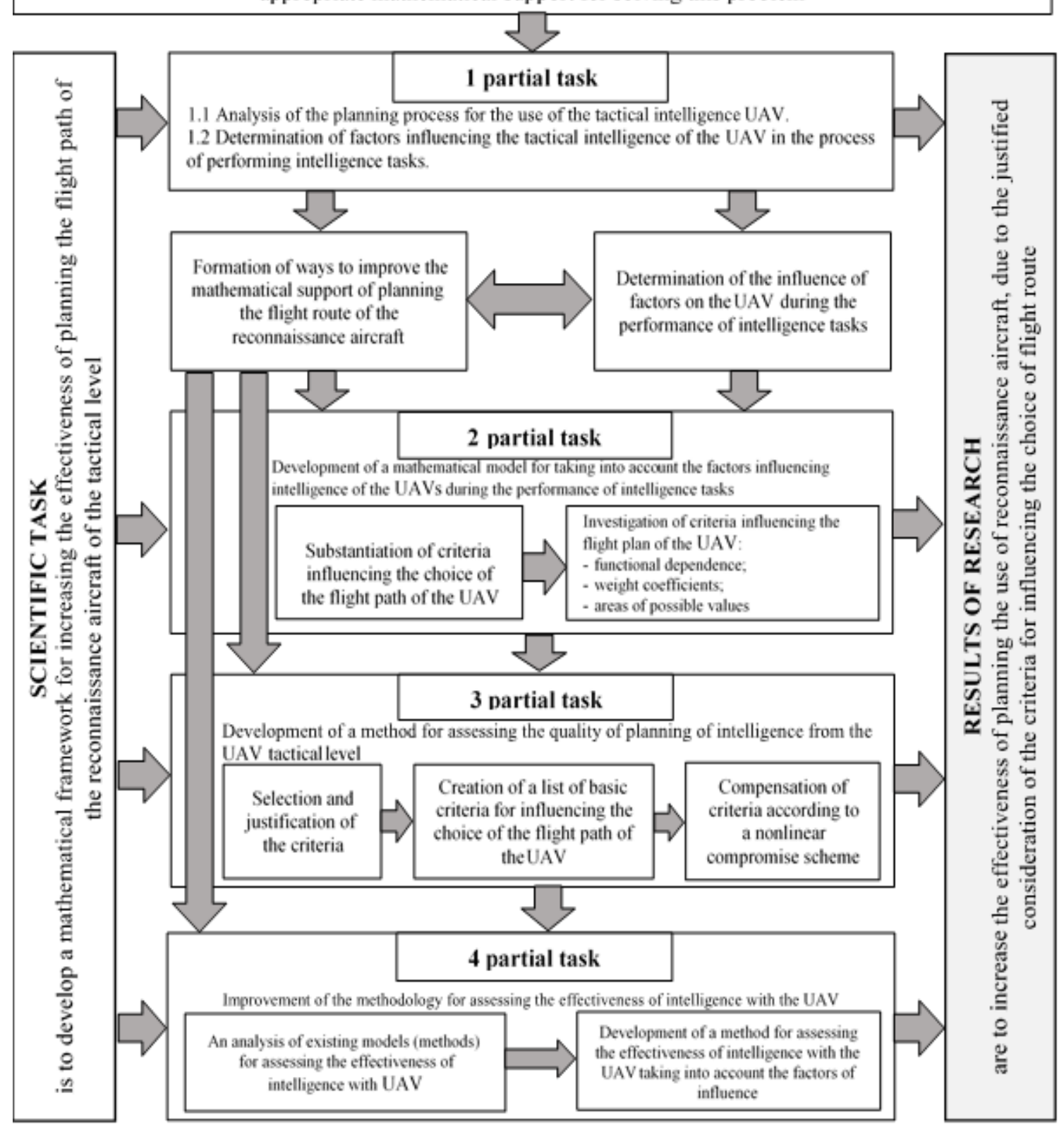

Figure 2 - Structural-logical scheme of the research 
The advantages of this scheme are visibility and step-by-step implementation of partial research tasks. It allows you to understand the input and the number of key steps that each stage includes. The peculiarity is the prediction of the result, which should be obtained after the research completion.

\section{CONCLUSIONS}

For the first time, a scientific task was put forward, in a formalized form, which is to increase the effectiveness of planning the flight route of the special purpose of unmanned aerial vehicles tactical level in conditions of a concrete combat picture. A perspective direction for further research is the development of a mathematical model for taking into account the factors of influence on the reconnaissance unmanned aerial vehicles during the performance of intelligence tasks and the creation a method for assessing the quality of intelligence planning for the unmanned aerial vehicles of a tactical level.

\section{REFERENCES}

1. Beard, R., \& McLain, T. (2015). Small Unmanned Aircraft. Moscow: Tehnosfera.

2. Buriachok, V., Hryshchuk, R., Mamariev, V. (2015). Construction method of cyber attacks classifier on government information resources. Technology audit and production reserves, 1(2), 38-43. doi: 10.15587/2312-8372.2015.37423 (in Ukrainian).

3. Eremin, G., Gavrilov, A., \& Nazarchuk, I. (2015, January 29). Malorazmernye bespilotniki - novaja problema dlja PVO [Small Unmanned Aircraft - a new problem for air defense]. Retrieved from http://otvaga2004.ru/armiya-i-vpk/armiya-i-vpk-vzglyad/malorazmernye-bespilotniki (in Russian).

4. Feoktistov, D., \& Aleshechkin, A. (2013). Issledovanie algoritmov reshenija navigacionnyh zadach [Research of algorithms for solving navigation problems]. Retrieved from http://research.sfukras.ru/publications/publication/192680249-363657645 (in Russian).

5. Grebennikov, A. (Ed). (2008). Obshhie vidy i harakteristiki bespilotnyh letatel'nyh apparatov [General types and characteristics of unmanned aerial vehicles]. Kharkov: Har'kovskij aviacionnyj institut (in Russian).

6. Gubanov, V., Zaharov, V., \& Kovalenko, A. (1988). Vvedenie v sistemnyj analiz [Introduction to system analysis]. Leningrad: LGU (in Russian).

7. Hryshchuk, R., \& Molodetska-Hrynchuk, K. (2018). Postanovka problemy zabezpechennia informatsiinoi bezpeky derzhavy u sotsialnykh Internet-servisakh [Resolving the problem of providing information security of state in social networking services]. Modern Information Security, 1(33), 43-52 (in Ukrainian).

8. Hryshchuk, R., \& Okhrimchuk, V. (2015). Postanovka naukovoho zavdannia z rozroblennia shabloniv potentsiino nebezpechnykh kiberatak [Formulation of the scientific tasks for the potentially dangerous patterns of cyber-attacks development]. Ukrainian Scientific Journal of Information Security, 21(3), 276-282 (in Ukrainian).

9. Moiseev, V. (2015). Osnovy teorii jeffektivnogo primenenija bespilotnyh letatel'nyh apparatov [Fundamentals of the theory of the effective use of unmanned aerial vehicles]. Kazan': Shkola (in Russian).

10. Shcherbinin, R. (n. d.). Vidomosti pro zastosuvannia RPA u armii USA [Information on the use of RPA in the US Army]. Retrieved December 1, 2018, from https://mil.in.ua/pohliady-komanduvanniaps-ssha-na-pidvyshch (in Ukrainian).

11. Voronin, A., Ziatdinov, Ju., \& Kuklinskij, M. (2011). Mnogokriterial'nye reshenija: modeli i metody [Multi-criteria solutions: models and methods]. Kiev: Nacional'nyj aviacionnyj universitet (in Russian). 
12. Yevseiev, S. (2016). Synerhetychnyi pidkhid do otsinky bezpeky bankivskykh system [The synergetic approach for bank systems' security assesment]. Systemy obrobky informatsii, 4(141), 90-103 (in Ukrainian).

13. Zgurec, S. (2015). Oruzhie Ukrainy. Bespilotniki: prizyv na vojnu [Weapons of Ukraine. UAVs: Call to War]. Kiev: Defense Express (in Russian). 